\title{
A survey of physician receptivity to molecular diagnostic testing and readiness to act on results for early-stage colon cancer patients
}

\author{
Ronald E. Myers ${ }^{1 *}\left(\mathbb{D}\right.$, Thomas Wolf ${ }^{1}$, Phillip Shwae ${ }^{2}$, Sarah Hegarty ${ }^{3}$, Stephen C. Peiper ${ }^{4}$ and Scott A. Waldman ${ }^{3}$
}

\begin{abstract}
Background: We sought to assess physician interest in molecular prognosic testing for patients with early stage colon cancer, and identify factors associated with the likelihood of test adoption.

Methods: We identified physicians who care for patients with early-stage (pNO) colon cancer patients, mailed them a survey, and analyzed survey responses to assess clinician receptivity to the use of a new molecular test (GUCY2C) that identifies patients at risk for recurrence, and clinician readiness to act on abnormal test results.

Results: Of 104 eligible potential respondents, 41 completed and returned the survey. Among responding physicians, $56 \%$ were receptive to using the new prognostic test. Multivariable analyses showed that physicians in academic medical centers were significantly more receptive to molecular test use than those in non-academic settings. Forty-one percent of respondents were ready to act on abnormal molecular test results. Physicians who viewed current staging methods as inaccurate and were confident in their capacity to incorporate molecular testing in practice were more likely to say they would act on abnormal test results.

Conclusions: Physician receptivity to molecular diagnostic testing for early-stage colon cancer patients is likely to be influenced by practice setting and perceptions related to delivering quality care to patients.
\end{abstract}

Trial registration: ClinicalTrials.gov Identifier: NCT01972737

Keywords: Decision analysis, Cancer, Colon carcinogenesis, Molecular genetics, Staging

\section{Background}

Advances in identifying novel markers and related clinical targets, along with the emergence of new diagnostic techniques and the development of pharmacologic antagonists of key signaling elements have generated expectations of dramatic change in the care of patients diagnosed with cancer. New and emerging molecular diagnostic tests have the potential to improve the accuracy of disease staging, determine if a given patient may be predisposed to disease progression, and provide useful information about the patient's likely response to treatment.

\footnotetext{
* Correspondence: Ronald.Myers@jefferson.edu

${ }^{1}$ Department of Medical Oncology, Thomas Jefferson University, Benjamin Franklin House, Suite 314, 834 Chestnut St, Philadelphia, PA 19107, USA Full list of author information is available at the end of the article
}

In the age of personalized medicine, patients are becoming increasingly aware of and are asking physicians about the value of such testing. Physicians who care for cancer patients are challenged by the need to learn about new developments in the field and the demand to apply these new tools in patient care [1]. Realizing the potential benefits of molecular diagnostic testing in cancer care will require high levels of physician receptivity and readiness to use such tests routinely $[2,3]$. To date, however, limited research has reported on physician receptivity to and use of molecular diagnostic testing in cancer care [4].

In a recent survey, $75 \%$ of physicians who treat cancer patients said they believe the use of genomic testing can improve patient care. However, respondents also stated that they had ordered genomic testing for only $4 \%$ of 
their patients [5]. In another study, $90 \%$ of respondents reported that they supported genomic testing, but less than half felt confident in their ability to interpret the test results to their patients [6]. Similar findings were noted by Stanek et al. [7] who found that $98 \%$ of physicians surveyed viewed molecular risk assessment as having the potential to play a crucial role in determining drug therapies for patients, but only $10 \%$ felt confident in their understanding to best use test results to guide the process of prescribing treatment.

The study reported here focuses on guanylate cyclase C (GUCY2C) testing, a new molecular diagnostic test that has been developed for use in conjunction with histopathology to guide treatment decision making for patients with early-stage (pNO) colon cancer. Conventional histopathological analysis for such patients is routinely triggered at the time of diagnosis ("reflex tests"), and therapy is to a large degree based on the pathologic stage that is determined. GUCY2C is a protein expressed normally by intestinal epithelial cells, but is universally over-expressed by metastatic colon tumors [8-10]. There is a strong association between the expression of GUCY2C in regional lymph nodes, measured using a validated quantitative RT-PCR assay [11], and the development of recurrent metastatic disease in otherwise lymph node-negative patients [12, 13]. Moreover, this test has been externally validated and commercialized [14-17].

The current investigation was part of a larger clinical trial (NCT01972737), which focused on the utility of GUCY2C as a vaccine target for the secondary prevention of metastatic colorectal cancer. Here, we collected and analyzed survey data from clinicians in the Greater Philadelphia Area who treat colon cancer patients. Main objectives were to: (1) assess physician receptivity to GUCY2C testing, (2) assess physician readiness to act on test results, and (3) identify factors associated with test receptivity and readiness to act.

\section{Methods}

The research team initially obtained from the Department of Strategy and Business Development at Thomas Jefferson University a mailing list of medical oncologists, surgeons, and gastroenterologists practicing in the Greater Philadelphia Area. Following established methods [18], we sent all physicians on the mailing list an introductory letter that described the purpose of the study and invited response via provision of written consent. In addition, we requested that recipients of the invitation complete and return an enclosed survey questionnaire using a postagepaid return envelope or to complete an online version of the survey. The mailing also advised the recipient that $\mathrm{s} / \mathrm{he}$ would be compensated (\$125) for completion of the survey. We also included a postcard in the mailing that allowed the recipient to opt-out of the study. A month after this initial mailing, the research team sent non-respondents another study invitation, which included a copy of the survey questionnaire, an opt-out card, and a return envelope. At 60 days, the research team attempted to contact nonrespondents by telephone to encourage response.

At the beginning of the survey, GUCY2C and testing were described as follows: "GUCY2C is a protein expressed normally by intestinal epithelial cells, but is universally over-expressed by metastatic colon tumors. There is a relationship between the categorical (yes/no) presence of occult tumor cells in lymph nodes detected by GUCY2C testing and prognosis in pNO colon cancer. This paradigm has been used to quantify occult tumor burden in nodes. The GUCY2C test could be ordered for colon cancer patients at the time of surgery. Results of this test could be used in conjunction with histopathology to inform the clinical decision to or not to recommend chemotherapy." Survey items that operationalized constructs drawn from an explanatory framework known as the Diagnostic Evaluation Model (DEM) [19] followed this scenario.

DEM items measured factors that could help to explain physician receptivity to GUCY2C testing and readiness to act on test results. These factors include physician practice environment, sociodemographic background characteristics and experience, perceptions about testing, and perceptions about treatment. Regarding practice environment, respondents were asked whether they practiced mainly in an academic medical center, community-based hospital, and other practice settings. We asked respondents to provide information on background characteristics (i.e., age, gender, race, ethnicity, and years in practice) and experience caring for colon cancer patients (i.e., exposure to pN0 colon cancer patients and patients who experienced recurrence).

To elicit perceptions about testing, we asked respondents to report how accurate they thought histopathology, GUCY2C testing, and combined histopathology and $\mathrm{GUCY} 2 \mathrm{C}$ testing are in staging pNO colon cancer patients (i.e., not accurate, somewhat accurate, very accurate). In addition, we asked whether physicians agreed (Strongly Disagree - 1 versus Strongly Agree 5) that each of these three approaches to testing could provide sufficient information that was needed to recommend treatment. An item that assessed respondent agreement with the view that current testing methods were sufficiently accurate for $\mathrm{pN} 0$ colon cancer patients was also included.

Respondent perceptions about treatment were measured by assessing physician stress from uncertainty using five items from the Physicians' Reactions to Uncertainty (PRU) scale $(\alpha=0.59)$ [20]. Single items were used to measure physician perceived ease of making a treatment decision for pN0 colon cancer patients, confidence 
in identifying an effective treatment for early-stage colon cancer patients, and confidence that molecular diagnostic testing could improve patient treatment.

We assessed physician interest in the new test along two dimensions, receptivity and readiness to act. Specifically, we determined physician receptivity to the test by eliciting level of agreement (Strongly Disagree - 1 to Strongly Agree - 5) with the following statements: "I think GUCY2C test results should be considered when treatment is recommended for pNO colon cancer patients." and "I think all patients with pNO colon cancer should have a GUCY2C test." The summed mean responses to these items were dichotomized as $\leq 3$ (disagree or neutral) versus $>3$ (agree) to determine clinician receptivity to the use of GUC2YC testing. Survey respondents were determined to be receptive to testing if the mean response to the two survey items was $>3$. In terms of readiness to act, we asked physicians to respond to the following statement: "I would treat patients with pNO colon cancer who have abnormal GUCY2C test results more aggressively than patients with a normal test result." Responses were dichotomized as $\leq 3$ (disagree or neutral) versus $>3$ (agree)" to measure clinician readiness to act on abnormal test results. Physicians were considered to be ready to act on abnormal test results if their response to this single item was $>3$. Finally, we included open-ended questions that allowed respondents to report factors that would influence them to order GUCY2C testing.

Fisher's Exact testing was used to assess statistically significant associations between categorical variables and the two outcomes, while the Wilcoxon test was used to assess associations of continuous variables with outcomes. Covariates associated with the outcome variables at the $p \leq 0.2$ level were included in a multivariable logistic regression models. Backwards selection was used to determine the model, with retention of those independent variables that were associated at $p$-value of 0.05 . Because of the small sample size, exact $p$-values are reported.

Members of the research team (RM, TW, and PS) reviewed comments reported by physicians on the factors that would influence them to and not to order testing, and generated a set of unique factor categories. Independently, TW and PS assigned each factor to a category and then resolved any discrepancies in joint consultation with RM. Category frequencies were generated.

\section{Results}

A total of 211 physicians were targeted to receive the mailed survey. Feedback from that initial mailing, a subsequent reminder mailing, and a final telephone reminder resulted in the exclusion of 60 physicians with incomplete contact information. Additionally, 47 individuals were excluded, because they reported that they did not currently see pNO colon cancer patients, and two physicians were found to be deceased. Thus, there were 104 physicians who were eligible and available to complete the mailed survey. Of this number, 43 (41\%) completed the survey, 18 (17\%) declined to participate, and 43 (41\%) were lost to follow-up. The research team decided to remove two gastroenterologists from the pool of respondents because it was determined that physicians in this specialty are unlikely to recommend molecular testing for cancer patients following initial diagnosis. Thus, 41 respondents were included in the final analyses.

Survey DEM measures are displayed in Table 1. Study outcomes displayed in Table 1 show that overall, $51 \%$ of respondents were $<50$ years of age; $83 \%$ were male; and $68 \%$ were white. Forty-nine percent of physicians agreed that GUCY2C test results should be used to guide treatment recommendations for patients with early-stage colon cancer, and $44 \%$ percent agreed that all earlystage colon cancer patients should have such testing. A total of 18 respondents had a two-item summed mean response $\leq 3$, and 22 respondents had a summed receptivity score that was $>3$. The respective percentage of respondents in these categories, which are not included in the table, are 44 and $56 \%$, respectively. The numbers of respondents in these categories corresponds to the table column headings for the outcomes.

In univariable analyses (Table 1), the following variables were associated with physician receptivity to GUCY2C testing: practice located in an academic medical center $(p=0.004)$; belief that the combined results of histopathology and GUCY2C testing could provide information needed to recommend treatment ( $p=0.038)$; belief that GUCY2C testing alone, as well as combined histopathology and GUCY2C testing were somewhat or very accurate $(p=0.133$ and $p=0.054$, respectively); and belief that making treatment decisions for $\mathrm{pN} 0$ colon cancer patients is easy $(p=0.009)$. Multivariable analysis results (Table 2) indicate that physicians who practiced in academic medical centers were more receptive to GUCY2C testing than those who practiced in community hospitals or other settings (OR $=7.14$, CI: $1.28,55.02)$.

In terms of readiness to act (Table 3), there were 24 physicians had a response $\leq 3$, while 17 clinicians who had a response to the one item used to assess readiness that was $>3$. The respective percentages of respondents in these categories, which are not displayed in the table, are 59 and $41 \%$, respectively. Univariable analyses showed the following variables to be associated with physician readiness to act on abnormal test results: race $(p=0.103)$; belief that GUCY2C testing alone and the 
Table 1 Univariable associations of physician receptivity to genomic risk assessment (GUCY2C) for pN0 colon cancer patients

\begin{tabular}{|c|c|c|c|c|}
\hline & $\begin{array}{l}\text { Total } \\
(n=41)\end{array}$ & $\begin{array}{l}\text { Receptive } \\
(n=22)\end{array}$ & $\begin{array}{l}\text { Not Receptive } \\
(n=19)\end{array}$ & $p$-value \\
\hline & n (\%) & n (\%) & n (\%) & \\
\hline \multicolumn{5}{|l|}{ Practice Environment: } \\
\hline Practice Setting & & & & 0.004 \\
\hline Community-based or Other & $24(58.54)$ & $8(33.33)$ & $16(66.67)$ & \\
\hline Academic Center-based & $17(41.46)$ & $14(82.35)$ & $3(17.65)$ & . \\
\hline \multicolumn{5}{|l|}{ Sociodemographic Background and Experience: } \\
\hline Age & & & & 1.000 \\
\hline$<50$ & $21(51.22)$ & $11(52.38)$ & $10(47.62)$ & . \\
\hline $50+$ & $20(48.78)$ & $11(55.00)$ & $9(45.00)$ & . \\
\hline Gender & & & & 0.219 \\
\hline Male & $34(82.93)$ & $20(58.82)$ & $14(41.18)$ & \\
\hline Female & $7(17.07)$ & $2(28.57)$ & $5(71.43)$ & . \\
\hline Race & & & & 1.000 \\
\hline (missing/unknown) & $1()$. & $0()$. & $1()$. & . \\
\hline Asian & $13(32.50)$ & $7(53.85)$ & $6(46.15)$ & . \\
\hline White & $27(67.50)$ & $15(55.56)$ & $12(44.44)$ & . \\
\hline Hispanic/Latino & & & & 0.463 \\
\hline No & $40(97.56)$ & $22(55.00)$ & $18(45.00)$ & . \\
\hline Yes & $1(2.44)$ & & $1(100.0)$ & . \\
\hline Years in Practice & & & & 0.891 \\
\hline$<=10$ & $4(9.76)$ & $2(50.00)$ & $2(50.00)$ & \\
\hline $10-20$ & $11(26.83)$ & $5(45.45)$ & $6(54.55)$ & . \\
\hline$>20$ & $26(63.41)$ & $15(57.69)$ & $11(42.31)$ & \\
\hline Specialty & & & & 0.758 \\
\hline Medical Oncologists+ & $23(56.10)$ & $13(56.52)$ & $10(43.48)$ & \\
\hline Gl Surgeons & $18(43.90)$ & $9(50.00)$ & $9(50.00)$ & . \\
\hline Number of newly diagnosed pNO colon cancer patients seen in past 12 months & & & & 0.668 \\
\hline$<5$ & $6(14.63)$ & $4(66.67)$ & $2(33.33)$ & . \\
\hline $5+$ & $35(85.37)$ & $18(51.43)$ & $17(48.57)$ & . \\
\hline Percentage of pNO colon cancer patients who have had a recurrence in the past 12 months & & & & 1.000 \\
\hline None & $20(48.78)$ & $11(55.00)$ & $9(45.00)$ & . \\
\hline $1+$ & $21(51.22)$ & $11(52.38)$ & $10(47.62)$ & \\
\hline On average how many pNO colon cancer patients do you see each month? & & & & 0.737 \\
\hline$<5$ & $28(68.29)$ & $16(57.14)$ & $12(42.86)$ & . \\
\hline $5+$ & $13(31.71)$ & $6(46.15)$ & $7(53.85)$ & . \\
\hline \multicolumn{5}{|l|}{ Perceptions about Diagnostic/Prognostic Testing: } \\
\hline Belief in accuracy of histopathology & & & & 1.000 \\
\hline Not Agree & $14(34.15)$ & $8(57.14)$ & $6(42.86)$ & . \\
\hline Agree & $27(65.85)$ & $14(51.85)$ & $13(48.15)$ & . \\
\hline Belief in accuracy of GUY2C testing & & & & 0.216 \\
\hline Not Agree & $17(41.46)$ & $7(41.18)$ & $10(58.82)$ & . \\
\hline Agree & $24(58.54)$ & $15(62.50)$ & $9(37.50)$ & . \\
\hline
\end{tabular}


Table 1 Univariable associations of physician receptivity to genomic risk assessment (GUCY2C) for pN0 colon cancer patients (Continued)

\begin{tabular}{|c|c|c|c|c|}
\hline \multicolumn{4}{|l|}{ Belief in accuracy of combined histopathology and GUCY2C testing } & \multirow[t]{2}{*}{0.038} \\
\hline Not Agree & $4(9.76)$ & $0(0.0)$ & $4(100.0)$ & \\
\hline Agree & $37(90.24)$ & $22(59.46)$ & $15(40.54)$ & . \\
\hline Belief in need for a more accurate prognostic test for pNO colon cancer patients & & & & 1.000 \\
\hline Not Agree & $2(4.88)$ & $1(50.00)$ & $1(50.00)$ & . \\
\hline Agree & $39(95.12)$ & $21(53.85)$ & $18(46.15)$ & \\
\hline Belief that current staging methods are not accurate for pNO colon cancer patients & & & & 0.216 \\
\hline Not Agree & $17(41.46)$ & $7(41.18)$ & $10(58.82)$ & . \\
\hline Agree & $24(58.54)$ & $15(62.50)$ & $9(37.50)$ & . \\
\hline Accuracy of histopathology alone & & & & 0.388 \\
\hline (missing/unknown) & $1()$. & $0()$. & $1()$. & \\
\hline Very Accurate & $6(15.00)$ & $3(50.00)$ & $3(50.00)$ & . \\
\hline Somewhat Accurate & $31(77.50)$ & $16(51.61)$ & $15(48.39)$ & . \\
\hline Not Accurate & $3(7.50)$ & $3(100.0)$ & $0(0.0)$ & . \\
\hline Don't know & $0(0.0)$ & $0(0.0)$ & $0(0.0)$ & . \\
\hline Accuracy of GUCY2C testing alone & & & & 0.133 \\
\hline (missing/unknown) & $2()$. & $0()$. & $2()$. & . \\
\hline Very Accurate & $6(15.38)$ & $4(66.67)$ & $2(33.33)$ & \\
\hline Somewhat Accurate & $22(56.41)$ & $13(59.09)$ & $9(40.91)$ & . \\
\hline Not Accurate & $3(7.69)$ & $3(100.0)$ & $0(0.0)$ & \\
\hline Don't Know & $8(20.51)$ & $2(25.00)$ & $6(75.00)$ & . \\
\hline Accuracy of combined histopathology and GUCY2C testing & & & & 0.054 \\
\hline (missing/unknown) & $1()$. & $0()$. & $1()$. & . \\
\hline Very Accurate & $25(62.50)$ & $16(64.00)$ & $9(36.00)$ & . \\
\hline Somewhat Accurate & $11(27.50)$ & $6(54.55)$ & $5(45.45)$ & \\
\hline Not Accurate & $0(0.0)$ & $0(0.0)$ & $0(0.0)$ & \\
\hline Don't Know & $4(10.00)$ & $0(0.0)$ & $4(100.0)$ & \\
\hline \multicolumn{5}{|l|}{ erceptions about Treatment: } \\
\hline Stress from uncertainty in decision making about treatment for pNO colon cancer patients (scale) & & & & 0.350 \\
\hline Not Agree $(<=3)$ & $22(53.66)$ & $10(45.45)$ & $12(54.55)$ & . \\
\hline Agree $(>3)$ & $19(46.34)$ & $12(63.16)$ & $7(36.84)$ & . \\
\hline Belief that treatment decision making for pNO colon cancer patients is easy & & & & 0.009 \\
\hline Not Agree & $13(31.71)$ & $11(84.62)$ & $2(15.38)$ & . \\
\hline Agree & $28(68.29)$ & $11(39.29)$ & $17(60.71)$ & . \\
\hline Confidence in treatment decision making for pNO colon cancer patients & & & & 0.325 \\
\hline Not Agree & $12(29.27)$ & $8(66.67)$ & $4(33.33)$ & . \\
\hline Agree & $29(70.73)$ & $14(48.28)$ & $15(51.72)$ & . \\
\hline Belief that treatment choice for pNO colon cancer patients is clear & & & & 0.756 \\
\hline Not Agree & $19(46.34)$ & $11(57.89)$ & $8(42.11)$ & \\
\hline Agree & $22(53.66)$ & $11(50.00)$ & $11(50.00)$ & . \\
\hline
\end{tabular}

combined results of histopathology and GUCY2C testing could provide information needed to recommend treatment ( $p=0.012$ and $p=0.128$, respectively); belief that current staging methods are not accurate for pN0 colon cancer patients (0.062); belief that GUCY2C testing alone, as well as the combined results of histopathology and 
Table 2 Multivariable logistic regression on combined D1, D3 outcome (D1, D3 mean >3) $(N=41)$

\begin{tabular}{lllll}
\hline Exact odds ratios & & & \\
\hline Parameter & Estimate & $95 \%$ Confidence limits & Two-sided $p$-value \\
\hline $\begin{array}{l}\text { How would you describe your practice setting? } \\
\text { Hospital-based vs. Community Based/Other }\end{array}$ & 7.14 & 1.28 & 55.02 & 0.021 \\
\hline
\end{tabular}

GUCY2C testing are somewhat or very accurate $(p=0.179$ and $p=0.084$, respectively); belief that treatment choice is clear $(p=0.025)$.

Multivariable analysis results (Table 4) indicate that physicians respondents who thought that current staging methods for pNO colon patients were not sufficiently accurate were more likely to report that they would act on abnormal GUCY2C test results than those who did not hold this belief $(\mathrm{OR}=5.98, \mathrm{CI}: 1.05,49.32)$. In addition, physicians who stated that it was clear what treatment choice is correct for their patients were significantly more likely to say they would act on GUY2C test results than those who were less confident (OR = 7.74, CI: 1.41, 62.20).

All 41 physicians responded to the open-ended survey question that asked them to indicate the factors that would discourage them from recommending GUCY2C testing. Together, the respondents identified a total of 85 factors. Of this number, 31 (36\%) factors related to having insufficient information about test accuracy; 26 (31 \%) expressed concern about the cost of such testing; $22(26 \%)$ said they were were not familiar with guidelines that specified circumstances for test use; and 9 (11 \%) reported that they did not think the test was readily available.

\section{Discussion}

This study is the first to measure physician interest in molecular testing in terms of receptivity and readiness to act on test results. In addition, the study is novel in that it focuses attention on the testing for early-stage colon cancer patients. Moreover, the study used an explanatory framework (DEM) to identify factors that influence physician receptivity to test use and readiness to act on test results.

We found that $44 \%$ of surveyed physicians were receptive to GUCY2C testing for patients with earlystage colon cancer. To our knowledge, this report is the first instance in which physician receptivity to prognostic molecular diagnostic testing in this patient population been assessed. Elsewhere, it has been reported that more than half of physicians who treat metastatic colorectal cancer patients ordered a genetic test for their patients after it was cited in clinical guidelines [2]. This level of interest in molecular diagnostic testing suggests that many physicians who treat early-stage patients see a need to improve on existing staging methods, and have a desire to consider test results in treatment planning.

We also determined that physicians who practiced at academic medical centers were more enthusiastic about molecular testing for risk of recurrence than their counterparts in community hospital settings. This finding may reflect the fact that molecular diagnostic testing is more readily available in academic medical centers than in community settings, as such testing can be provided in-house. As a result, tests in academic settings can be performed easily and their results obtained in a timely manner to inform physician recommendations. It may also be the case that there may be more opportunities for physicians in academic medical centers to share information about new molecular diagnostic tests, personal experiences using the tests, and patient outcomes. As a result, academic medical center-based physicians may feel a greater sense confidence in using the tests in routine care.

Forty-one percent of physicians in the current study reported that they were ready to treat patients with an abnormal GUYC2C test result more aggressively than patients who had a normal test result. We found that physicians who were ready to act on GUCY2C test results were more likely to question the accuracy of current staging methods than physicians who were not ready to act of test results. Notably, $90 \%$ of physicians reported that the combined histopathology and molecular diagnostic testing could provide sufficient information to allow them to make good treatment decisions. Most physicians tended to view molecular diagnostic testing as providing them with additional information that, in conjunction with current histopathology results, could help to better-forecast recurrence, and improve their capacity to recommend the most appropriate treatment. In the context of the current investigation, we found that respondents who reported being ready to treat patients with abnormal GUCY2C results more aggressively were more likely to believe that molecular testing could improve their capacity to provide high quality care to their patients.

Physician readiness to act on abnormal test results may be influenced to some extent by practitioner feelings of stress from uncertainty about treating early-stage colon cancer patients on the basis of histopathology analyses alone, and confidence in 
Table 3 Univariable associations of physician readiness to act on genomic risk assessment (GUCY2C) for pNO colon cancer Patients

\begin{tabular}{|c|c|c|c|c|}
\hline \multirow[t]{2}{*}{ Variable } & \multirow{2}{*}{$\begin{array}{l}\text { Total } \\
(n=41) \\
\mathrm{n}(\%) \\
\end{array}$} & \multirow{2}{*}{$\begin{array}{l}\text { Ready } \\
(n=17) \\
\mathrm{n}(\%)\end{array}$} & \multirow{2}{*}{$\begin{array}{l}\text { Not ready } \\
(n=24) \\
\mathrm{n}(\%)\end{array}$} & \multirow[t]{2}{*}{$p$-value } \\
\hline & & & & \\
\hline \multicolumn{5}{|l|}{ Practice Environment: } \\
\hline Practice Setting & & & & 0.748 \\
\hline Community-based or Other & $24(58.54)$ & $9(37.50)$ & $15(62.50)$ & \\
\hline Academic Center-based & $17(41.46)$ & $8(47.06)$ & $9(52.94)$ & . \\
\hline \multicolumn{5}{|l|}{ Sociodemographic Background and Experience: } \\
\hline Age & & & & 0.350 \\
\hline$<50$ & $21(51.22)$ & $7(33.33)$ & $14(66.67)$ & . \\
\hline $50+$ & $20(48.78)$ & $10(50.00)$ & $10(50.00)$ & \\
\hline Gender & & & & 1.000 \\
\hline Male & $34(82.93)$ & $14(41.18)$ & $20(58.82)$ & \\
\hline Female & $7(17.07)$ & $3(42.86)$ & $4(57.14)$ & . \\
\hline Race & & & & 0.103 \\
\hline (missing/unknown) & $1()$. & & $1()$. & . \\
\hline Asian & $13(32.50)$ & $3(23.08)$ & $10(76.92)$ & . \\
\hline White & $27(67.50)$ & $14(51.85)$ & $13(48.15)$ & . \\
\hline Hispanic/Latino & & & & 1.000 \\
\hline No & $40(97.56)$ & $17(42.50)$ & $23(57.50)$ & \\
\hline Yes & $1(2.44)$ & & $1(100.0)$ & . \\
\hline Years in Practice & & & & 0.559 \\
\hline$<=10$ & $4(9.76)$ & $2(50.00)$ & $2(50.00)$ & . \\
\hline $10-20$ & $11(26.83)$ & $3(27.27)$ & $8(72.73)$ & . \\
\hline$>20$ & $26(63.41)$ & $12(46.15)$ & $14(53.85)$ & . \\
\hline Specialty & & & & 1.000 \\
\hline Medical Oncologists+ & $23(56.10)$ & $10(43.48)$ & $13(56.52)$ & \\
\hline Gl Surgeons & $18(43.90)$ & 7 (38.89) & $11(61.11)$ & . \\
\hline Number of newly diagnosed pNO colon cancer patients seen in past 12 months & & & & 0.679 \\
\hline$<5$ & $6(14.63)$ & $3(50.00)$ & $3(50.00)$ & . \\
\hline $5+$ & $35(85.37)$ & $14(40.00)$ & $21(60.00)$ & \\
\hline Percentage of pN0 colon cancer patients who have had a recurrence in the past 12 months & & & & 0.530 \\
\hline None & $20(48.78)$ & $7(35.00)$ & $13(65.00)$ & . \\
\hline $1+$ & $21(51.22)$ & $10(47.62)$ & $11(52.38)$ & . \\
\hline On average how many pNO colon cancer patients do you see each month? & & & & 0.499 \\
\hline$<5$ & $28(68.29)$ & $13(46.43)$ & $15(53.57)$ & . \\
\hline $5+$ & $13(31.71)$ & $4(30.77)$ & $9(69.23)$ & . \\
\hline \multicolumn{5}{|l|}{ Perceptions about Diagnostic/Prognostic Testing } \\
\hline Belief in accuracy of histopathology & & & & 0.742 \\
\hline Not Agree & $14(34.15)$ & $5(35.71)$ & $9(64.29)$ & . \\
\hline Agree & $27(65.85)$ & $12(44.44)$ & $15(55.56)$ & . \\
\hline Belief in accuracy of GUY2C testing & & & & 0.012 \\
\hline Not Agree & $17(41.46)$ & $3(17.65)$ & $14(82.35)$ & . \\
\hline Agree & $24(58.54)$ & $14(58.33)$ & $10(41.67)$ & . \\
\hline Belief in accuracy of combined histopathology and GUCY2C testing & & & & 0.128 \\
\hline
\end{tabular}


Table 3 Univariable associations of physician readiness to act on genomic risk assessment (GUCY2C) for pNO colon cancer Patients (Continued)

\begin{tabular}{|c|c|c|c|c|}
\hline Not Agree & $4(9.76)$ & & $4(100.0)$ & . \\
\hline Agree & $37(90.24)$ & $17(45.95)$ & $20(54.05)$ & . \\
\hline Belief in need for a more accurate prognostic test for pNO colon cancer patients & & & & 1.000 \\
\hline Not Agree & $2(4.88)$ & $1(50.00)$ & $1(50.00)$ & . \\
\hline Agree & $39(95.12)$ & $16(41.03)$ & $23(58.97)$ & . \\
\hline Belief that current staging methods are not accurate for pNO colon cancer patients & & & & 0.062 \\
\hline Not Agree & $17(41.46)$ & $4(23.53)$ & $13(76.47)$ & \\
\hline Agree & $24(58.54)$ & $13(54.17)$ & $11(45.83)$ & . \\
\hline Accuracy of histopathology alone & & & & 0.861 \\
\hline (missing/unknown) & $1()$. & $0()$. & $1()$. & . \\
\hline Very Accurate & $6(15.00)$ & $2(33.33)$ & $4(66.67)$ & . \\
\hline Somewhat Accurate & $31(77.50)$ & $14(45.16)$ & $17(54.84)$ & . \\
\hline Not Accurate & $3(7.50)$ & $1(33.33)$ & $2(66.67)$ & . \\
\hline Don't Know & $0(0.0)$ & $0(0.0)$ & $0(0.0)$ & \\
\hline Accuracy of GUCY2C testing alone & & & & 0.179 \\
\hline (missing/unknown) & $2()$. & $0()$. & $2()$. & . \\
\hline Very Accurate & $6(15.38)$ & $5(83.33)$ & $1(16.67)$ & . \\
\hline Somewhat Accurate & $22(56.41)$ & $9(40.91)$ & $13(59.09)$ & . \\
\hline Not Accurate & $3(7.69)$ & $1(33.33)$ & $2(66.67)$ & \\
\hline Don't Know & $8(20.51)$ & $2(25.00)$ & $6(75.00)$ & . \\
\hline Accuracy of combined histopathology and GUCY2C testing & & & & 0.084 \\
\hline (missing/unknown) & $1()$. & $0()$. & $1()$. & . \\
\hline Very Accurate & $25(62.50)$ & $14(56.00)$ & $11(44.00)$ & . \\
\hline Somewhat Accurate & $11(27.50)$ & $2(18.18)$ & $9(81.82)$ & . \\
\hline Not Accurate & $0(0.0)$ & $0(0.0)$ & $0(0.0)$ & \\
\hline Don't Know & $4(10.00)$ & $1(25.00)$ & $3(75.00)$ & . \\
\hline \multicolumn{5}{|l|}{ Perceptions about Treatment } \\
\hline Stress from uncertainty in decision making about treatment for pN0 colon cancer patients (scale) & & & & 0.216 \\
\hline Not Agree $(<=3)$ & $22(53.66)$ & $7(31.82)$ & $15(68.18)$ & . \\
\hline Agree $(>3)$ & $19(46.34)$ & $10(52.63)$ & $9(47.37)$ & . \\
\hline Belief that treatment decision making for pNO colon cancer patients is easy & & & & 0.499 \\
\hline Not Agree & $13(31.71)$ & $4(30.77)$ & $9(69.23)$ & . \\
\hline Agree & $28(68.29)$ & $13(46.43)$ & $15(53.57)$ & . \\
\hline Confidence in treatment decision making for pNO colon cancer patients & & & & 0.729 \\
\hline Not Agree & $12(29.27)$ & $4(33.33)$ & $8(66.67)$ & . \\
\hline Agree & $29(70.73)$ & $13(44.83)$ & $16(55.17)$ & . \\
\hline Belief that treatment choice for pNO colon cancer patients is clear & & & & 0.025 \\
\hline Not Agree & $19(46.34)$ & $4(21.05)$ & $15(78.95)$ & . \\
\hline Agree & $22(53.66)$ & $13(59.09)$ & $9(40.91)$ & \\
\hline
\end{tabular}

interpreting molecular test results. In other reports, physicians who have limited familiarity with molecular diagnostic testing have expressed uncertainty about their capacity to interpret and explain test results to their patients, and, as a consequence, may be more reluctant to support the use of such tests in practice $[4,6,7]$.

It is important to mention that the generalizability of findings reported here might be limited for several reasons. First, the survey response rate among eligible 
Table 4 Multivariable logistic regression of physician readiness to act on genomic risk assessment (GUCY2C) for pNo colon cancer patients $(N=41)$

\begin{tabular}{llll}
\hline Exact odds ratios & & & \\
\hline Parameter & Estimate & $\begin{array}{l}95 \% \text { Confidence } \\
\text { limits }\end{array}$ & $\begin{array}{l}\text { Two-sided } \\
p \text {-value }\end{array}$
\end{tabular}

It is clear what treatment choice is right for my patients.

$\begin{array}{lllll}\text { Agree vs. Do Not Agree } & 7.74 & 1.41 & 62.20 & 0.013\end{array}$

I am not satisfied with the accuracy of current approaches for staging my patients.

$\begin{array}{lllll}\text { Agree vs. Do Not Agree } & 5.98 & 1.05 & 49.32 & 0.042\end{array}$

physicians was less than $50 \%$. Therefore, survey responses may not be representative of physicians who care for patients diagnosed with early-stage colon cancer. In addition, the survey was administered to physicians in one geographic area; and, perceptions related to molecular diagnostic testing may reflect those held by practitioners in this region. In addition, the number of physicians who completed the survey is small, thus, findings from our analyses may be spurious. It is also the case that we collected data on only physician perceptions and receptivity to the use of only one molecular test for a specified set of cancer patients. Findings may vary if another type of test had been presented and a different set of patients were referenced. Social desirability in survey response may be another challenge to generalizabilty, as respondents could have been motivated to provide what they may viewed as a "correct" response to survey items.

\section{Conclusion}

Health care institutions and groups committed to developing state-of-the-art practice guidelines are placing greater emphasis on physician education about the use of laboratory-developed molecular tests in personalized medicine [21]. Research on a national cohort of clinicians is needed to identify factors that influence physician uptake of molecular testing for cancer patients and to determine the impact of test results on clinical recommendations that are made. Furthermore, research should also focus attention on assessing patient outcomes that result from using these new evidence-based diagnostic and prognostic methods.

In the future, there will be a steady increase in predictive molecular testing in cancer care. The adoption of such testing will be influenced by a variety of factors, including organizational factors and provider characteristics and perceptions. Teng et al. have concluded that evidence suggests that the adoption of molecular testing in routine care is most likely to take place when this service is performed as a laboratory test commonly performed at the time of diagnosis, rather than requiring a discretionary order for testing, and when payers routinely reimburse testing [22]. It is expected that ongoing efforts to include molecular diagnostic testing in clinical guidelines will add momentum to this process [23]. Findings reported in the current study highlight the need to address physician educational and decision support needs to advance the use of molecular testing.

Furthermore, the movement towards patient-centered care highlights the importance of physician-patient shared decision-making about diagnostic testing and treatment. Decision support interventions that are designed to provide patients with information, elicit values and preferences related to treatment options, and facilitate shared decision making must also be integrated into clinical practice. Centers of excellence in medical care must lead the way by deploying effective methods for overcoming structural obstacles, operational barriers, and individual limitations to molecular test uptake. This effort should include support for shared decision making in health systems and the prospective assessment of clinical outcomes.

\section{Abbreviations}

DEM: Diagnostic evaluation model; GUCY2C: Guanylate cyclase C; IRB: Institutional review board; pNO: No regional lymph node metastasis identified histologically; PRU: Physicians' reactions to uncertainty

\section{Acknowledgements}

The authors thank Thomas Jefferson University Department of Pathology, Anatomy and Cell Biology pathologists Drs. Jeffrey P. Baliff, MD, Juan P. Palazzo, MD, Wei Jiang, MD, and Anthony Prestipino, MD for completing a structured interview that aided in creation of the survey.

\section{Funding}

This project was funded, in part, under a grant with the Pennsylvania Department of Health (SAP \#4100059197), S. Waldman, PI. The Department specifically disclaims responsibility for any analyses, interpretations or conclusions.

ClinicalTrials.gov Identifier: NCT01972737.

\section{Availability of data and materials}

Data files and materials pertaining to this publication are available upon request at ronald.myers@jefferson.edu.

\section{Authors' contributions}

REM conceived of the study. REM and SAW initiated the study design. TW executed the implementation. REM and SAW are grant holders. SAW and SH provided statistical expertise in clinical trial design. SCP coordinated the structured interview portion of the project. PS and SH conducted the primary statistical analysis. All authors contributed to refinement of the study protocol and approved the final manuscript.

\section{Authors' information}

The lead author, REM, is a Professor in the Department of Medical Oncology, Thomas Jefferson University, Director: Kimmel Cancer Center Cancer Prevention \& Control, Director: Department of Medical Oncology, Division of Population Science. Dr. Myers has been actively involved in cancer prevention and has conducted cancer prevention, control, and population science research for over 25 years. He has been a principal investigator on more than $25 \mathrm{NIH}$-funded research grants and has numerous peer-reviewed publications in the field. His areas of expertise include patient adherence to cancer screening; physician follow-up of abnormal cancer screening test results; and informed and shared decision making in cancer screening, susceptibility testing and clinical trials participation. Currently, Dr. Myers leads a special populations project funded by the $\mathrm{NCl}$ Center for Reducing Cancer Health Disparities. 
The co-author, SAW, is Professor of Pharmacology \& Experimental Therapeutics, Chair of the Department of Biochemistry and Molecular Pharmacology, Thomas Jefferson University Jefferson Medical College, and Director of the Gl Malignancies Program, Kimmel Cancer Center. His research and clinical interests include molecular mechanisms regulating guanylyl cyclases, transcription factors mediating tissue-specific expression of proteins, molecular markers and cancer, cyclic GMP and the regulation of the cell cycle, differentiation, metabolic programming and DNA damage and repair, and experimental therapeutics. Dr. Waldman has been actively involved in the discovery and development of molecular diagnostics and targeted therapeutics in cancer for more than 25 years. During that time, he has been the principal investigator for more than 50 peer-reviewed research grants, including more than 10 clinical trials translating laboratory-based discoveries into clinical application. The co-author SCP is the Peter A. Herbut Professor, Chair of the Department of Pathology, Anatomy, and Cell Biology, at Thomas Jefferson University/Jefferson Medical College, Director of Clinical Laboratories, and Associate Director for Translational Research. Dr. Peiper has published over 160 peerreviewed publications and authored over 30 book chapters and symposia. In addition, Dr. Peiper served as a section editor for the Journal of Immunology and is currently on the editorial boards of Human Pathology and Biotechnology Healthcare. His specialty is Pathology - Anatomic \& Surgical and he is Board certified in Anatomic \& Clinical Pathology. His research interests include the molecular characterization of hematopoietic cells and their neoplastic counterparts and the application of emerging molecular technologies to diagnostic pathology.

\section{Competing interests}

The authors declare that they have no competing interests.

\section{Consent for publication}

Not Applicable. No details, images, or videos relating to individual participants are included in the manuscript.

\section{Ethics approval and consent to participate}

The study was approved by the institutional review board (IRB) of Thomas Jefferson University. Participating physicians provided written consent.

\section{Author details}

'Department of Medical Oncology, Thomas Jefferson University, Benjamin Franklin House, Suite 314, 834 Chestnut St, Philadelphia, PA 19107, USA.

${ }^{2}$ Thomas Jefferson University, 305 South 11th Street, Apt. 4F, Philadelphia, PA 19107, USA. ${ }^{3}$ Department of Pharmacology \& Experimental Therapeutics, Thomas Jefferson University, 1015 Chestnut Street Building, Suite M-100 Mezzanine, 1015 Chestnut Street, Philadelphia, PA 19107, USA. Department of Pathology, Anatomy and Cell Biology, Thomas Jefferson University, Jeff Hall, Room 279, 1020 Locust St, Philadelphia, PA 19107, USA.

\section{Received: 12 October 2015 Accepted: 23 September 2016}

\section{Published online: 03 October 2016}

\section{References}

1. Rubin R. Precision Medicine: The Future or Simply Politics? J Am Med Assoc. 2015;313(11):1089-91.

2. Harris JN, Liljestrand P, Alexander GL, et al. Oncologists' attitudes towards KRAS testing: a multisite study. Cancer Med. 2013;2(6):881-8.

3. Marzuillo C, De Vito C, Boccia S, et al. Knowledge, attitudes and behavior of physicians regarding genetic tests for breast and colorectal cancer. Prev Med. 2013:57:477-82.

4. Gray S, Hicks-Courant K, Cronin A, Rollins B, Weeks J. Physicians' Attitudes About Multiplex Tumor Genomic Testing. J Clin Oncol. 2014;32(13):1317-23.

5. Working Paper 7: Personalized Medicine: Trends and prospects for the new science of genetic testing and molecular diagnostics. In: Newsroom. UnitedHealth Group. 2012. http://www.unitedhealthgroup.com/ /media/ UHG/PDF/2012/UNH-Working-Paper-7.ashx (Accessed 21 Jul 2015).

6. Hunter A, Wright P, Capelli M, Kasaboski A, Surh L. Physician knowledge and attitudes towards molecular genetic (DNA) testing of their patients. Clin Genet. 1998:53:447-55.

7. Stanek EJ, Sanders CL, Taber KA, et al. Adoption of Pharmacogenomic Testing by US Physicians: Results of a Nationwide Survey. Nat Publ Group. 2012;91(3):450-8.
8. Carrithers SL, Parkinson SJ, Goldstein S, Park P, Robertson DC, Waldman SA. Escherichia coli heat-stable toxin receptors in human colonic tumors. Gastroenterology. 1994;107(6):1653-61.

9. Carrithers SL, Barber MT, Biswas S, Parkinson SJ, Park PK, Goldstein SD, Waldman SA. Guanylyl cyclase $C$ is a selective marker for metastatic colorectal tumors in human extraintestinal tissues. Proc Natl Acad Sci U S A. 1996;93(25):14827-32.

10. Carrithers SL, Parkinson SJ, Goldstein SD, Park PK, Urbanski RW, Waldman SA Escherichia coli heat-stable enterotoxin receptors. A novel marker for colorectal tumors. Dis Colon Rectum. 1996;39(2):171-81.

11. Schulz S, Hyslop T, Haaf J, Bonaccorso C, Nielsen K, Witek ME, Birbe R, Palazzo J, Weinberg D, Waldman SA. A validated quantitative assay to detect occult micrometastases by reverse transcriptase-polymerase chain reaction of guanylyl cyclase $C$ in patients with colorectal cancer. Clin Cancer Res. 2006:12(15):4545-52.

12. Waldman SA, Hyslop T, Schulz S, Barkun A, Nielsen K, Haaf J, Bonaccorso C, Li Y, Weinberg DS. Association of GUCY2C expression in lymph nodes with time to recurrence and disease-free survival in pN0 colorectal cancer. JAMA. 2009;301(7):745-52.

13. Hyslop T, Weinberg DS, Schulz S, Barkun A, Waldman SA. Occult tumor burden predicts disease recurrence in lymph node-negative colorectal cancer. Clin Cancer Res. 2011;17(10):3293-303.

14. Haince JF, Houde M, Beaudry G, L'Esperance S, Garon G, Desaulniers M, Hafer LJ, Heald Jl, Lyle S, Grossman SR, Tetu B, Sargent DJ, Fradet Y. Comparison of histopathology and RT-qPCR amplification of guanylyl cyclase C for detection of colon cancer metastases in lymph nodes. J Clin Pathol. 2010;63(6):530-7.

15. Sargent DJ, Resnick MB, Meyers MO, Goldar-Najafi A, Clancy T, Gill S, Siemons GO, Shi Q, Bot BM, Wu TT, Beaudry G, Haince JF, Fradet Y. Evaluation of guanylyl cyclase C lymph node status for colon cancer staging and prognosis. Ann Surg Oncol. 2011;18(12):3261-70.

16. Sargent DJ, Shi Q, Gill S, Louvet C, Everson RB, Kellner U, Clancy TE, Pipas $J M$, Resnick MB, Meyers MO, Wu TT, Huntsman D, Validire P, Farooq U, Pavey ES, Beaudry G, Haince JF, Fradet Y. Molecular testing for lymph node metastases as a determinant of colon cancer recurrence: results from a retrospective multicenter study. Clin Cancer Res. 2014;20(16):4361-9.

17. Gill S, Haince JF, Shi Q, Pavey ES, Beaudry G, Sargent DJ, Fradet Y. Prognostic Value of Molecular Detection of Lymph Node Metastases After Curative Resection of Stage II Colon Cancer: A Systematic Pooled Data Analysis. Clin Colorectal Cancer. 2015;14(2):99-105.

18. Dillman DA, Smyth JD, Christian LM. Internet, Phone, Mail, and Mixed-Mode Surveys: The Tailored Design Method Hardcover. Hoboken: Wiley; 2014.

19. Yabroff KR, Klabunde CN, Myers RE, Brown ML. Physician Recommendations for Follow-up of Positive Fecal Occult Blood Tests. Med Care Res Rev. 2005; 62(1):79-110.

20. Gerrity MS, DeVellis RF, Earp JA. Physicians' Reactions to Uncertainty in Patient Care. Med Care. 1990;28:724-36.

21. Engstrom PF, Bloom MG, Demetri GD, et al. NCCN Molecular Testing White Paper: Effectiveness, Efficiency, and Reimbursement. J Natl Compr Cancer Netw. 2011;9(Supplement 6):S1-16.

22. Teng K, Eng C, Hess CA, et al. Building an Innovative Model for Personalized Healthcare. Cleve Clin J Med. 2012;79(Supplement 1):1-9.

23. Guideline on the Evaluation of Molecular Markers for Colorectal Cancer Expert Panel Draft Recommendation Summary for Open Comment. http:// www.amp.org/committees/clinical_practice/documents/ 20150327CRCMMDraftRecommendationsforOCP-UPDATEDfinaldraft_001.pdf (Accessed 21 Jul 2015). 